\title{
Validación del Test de Identificación Emocional con música clásica: EMU
}

\author{
Anelia Ivanova Iotova y Virginia Jiménez Rodríguez \\ Universidad Complutense de Madrid (España)
}

\begin{abstract}
La música tiene un componente emocional intrínseco que la convierte en un lenguaje universal. Todas las personas reaccionan emocionalmente ante la música. Este estudio se propone exponer los resultados de la validación de un test llamado EMU que mide la capacidad de identificar emociones con fragmentos de música clásica, además de medir la percepción del tempo y la intensidad de la música. La muestra del estudio está compuesta por 514 estudiantes de dos universidades de España y Bulgaria que abarcan varias especialidades. Los resultados indican una fiabilidad moderada del test en conjunto $(\alpha=.60)$ y que las características musicales de intensidad y de tempo tienen una relación directa con la identificación emocional aunque ésta no sea significativamente relevante. Se puede concluir que una parte del test, la de identificación de emociones, es la que presenta una fiabilidad alta $(\alpha=.71)$. Así mismo se propone que el resto de las partes sigan siendo exploradas.
\end{abstract}

Palabras clave: Identificación emocional, emoción, música, música clásica, educación.

Validation of the Emotional Identification Test with Classical Music: EMU. Music has an intrinsic emotional component that makes it a universal language. All people react emotionally to music. This study aims to present the results of the validation of a test called EMU that measures the ability to identify emotions with fragments of classical music, in addition to measuring the perception of tempo and the intensity of music. The sample of the study is composed of 514 students from two universities in Spain and Bulgaria that cover several specialties. The results indicate a moderate reliability of the test as a whole $(\alpha=.60)$ and that the musical characteristics of intensity and tempo have a direct relationship with emotional identification although this is not significantly relevant. It can be concluded that part of the test, that of identifying emotions, is one that presents a high reliability $(\alpha=.71)$. Likewise, it is proposed that the rest of the parts continue to be explored.

Keywords: Emotional identification, emotion, music, classical music, education.

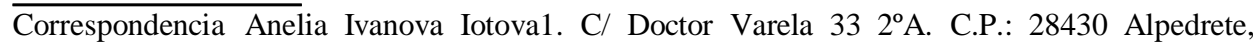
Madrid (España). E-mail: aivanova@ucm.es. 
Ya en épocas ancestrales la música pudo ser la actividad que preparaba para la comunicación verbal y la flexibilidad cognitiva. Ya era utilizada por los filósofos griegos para mejorar estados de ánimo en aquellas personas que lo necesitaban (Mosquera, 2013). El canto y las actividades desarrolladas con instrumentos ayudaron a la especie humana a perfeccionar habilidades motrices tanto gruesas como finas. La música de nuestros antepasados era ya muy rítmica y el ritmo es sabido que mueve el cuerpo. La música moviliza por lo que potencia los procesos psicomotrices llegando a influir en la organización de las relaciones espaciales (Lacárcel, 2003). La melodía y el tono musical mueven el cerebro por lo que la unión de la melodía y el ritmo hace que se agite el cerebro y el cuerpo simultáneamente, lo que provoca que la música conmueva al ser humano (Levitin, 2015).

Los beneficios que aporta la música en el área educativa son indiscutibles, por ejemplo, forjando hábitos de atención ante la novedad musical y agudizando la concentración (Lacárcel, 2003; Mosquera, 2013), pero en este trabajo se pretende conocer específicamente la validez de un test que relaciona la música y la emoción, haciendo hincapié en el aspecto de identificación emocional, habilidad incluida en el primer componente del modelo de Inteligencia Emocional de Salovey y Mayer (1990), ante una breve audición musical. La Inteligencia Emocional se define como la capacidad para percibir, asimilar, comprender y regular o manejar las propias emociones y las de los demás. Consta de cuatro componentes que se dan en orden creciente: a) percepción, expresión y evaluación emocional, que hace referencia a las emociones experimentadas por el sujeto y por las personas que le rodean; b) facilitación o asimilación emocional, que hace referencia a cómo influyen las emociones percibidas en el pensamiento; c) comprensión emocional, que hace referencia a la causa de las emociones; y d) regulación de las emociones, que hace referencia al manejo de las propias emociones y las de los demás (Jiménez, 2011).

Haciendo hincapié en el primer componente por ser el objeto de este estudio, la percepción emocional implica, entre otras cosas, saber identificar de manera conveniente las propias emociones y yendo más allá, las de los demás. Implica focalizar la atención en expresiones faciales, en movimientos del cuerpo y en la voz del emisor del mensaje (Fernández-Berrocal y Extremera, 2005) y parece que son las chicas las que tienen en mayor medida desarrollada esta destreza que forma parte de la llamada inteligencia emocional (Salovey y Mayer, 1990).

La música tiene la capacidad de producir placer o displacer, consideradas estas dimensiones de validación afectiva. Muchas personas experimentan una intensidad particular, una respuesta eufórica como respuesta a la música. Por ello, se puede decir que la música genera emoción. La emoción es una respuesta del organismo ante un estímulo concreto, un impulso que conduce a la acción. Sirve para adaptarse al medio en el que vive la persona que siente la emoción. Quizás el valor adaptativo que tiene la 
música radica en su beneficio para producir un estado de bienestar físico y mental. El comportamiento musical puede llegar a proporcionar satisfacción, llegando a producir felicidad (Lacárcel, 2003).

\section{Emociones y música}

Es interesante distinguir entre emociones primarias y secundarias. Las primarias o básicas son universales y se producen como una respuesta a un cambio específico en el estímulo que provoca la emoción. Su duración se mantiene mientras dura el estímulo. Después, se desvanece. Las emociones secundarias surgen debido al recuerdo de condiciones generadas en un ambiente específico. Estas suelen durar más que las primarias, ya que surgen como una anticipación a una situación que no tiene porqué llegar a darse (Fernández-Abascal, 2011). Se puede hablar, por ejemplo, del amor y de la tranquilidad o serenidad como emociones secundarias.

Entre las emociones básicas primarias se encuentran: la alegría, la tristeza, el miedo, la ira, el asco y la sorpresa. Cada una de ellas tiene una función específica (Ekman, 1992; Fernández-Abascal, 2011).

Como ejemplo, es sabido que la tristeza es una emoción primaria de las consideradas desagradables (aunque necesaria para adaptarse a nuevas situaciones de pérdida) y como tal una de sus características es que se mantiene más en el tiempo y es más frecuente que las agradables porque en la vida diaria se dan más situaciones frustrantes que satisfactorias (Vallés y Vallés, 2000) por lo que el individuo puede que tenga mayor facilidad para identificar esta emoción.

Mohn, Argstatter, y Wilker (2011) llegan a la conclusión que estas emociones básicas se pueden percibir por sujetos a los que se les presentan audiciones musicales desconocidas para ellos. Esto los lleva a aseverar que estas emociones pueden ser detectadas en la música. Otra investigación realizada con una tribu de Camerún que no había estado expuesta a música occidental concluyó que hay tres emociones básicas que son reconocidas universalmente a través de la música: la alegría, la tristeza y el miedo (Fritz et al., 2009).

El estado de ánimo, en muchas ocasiones, se ve reflejado por el tipo de música que se escucha e incluso se puede generar determinado estado de ánimo si se escucha una música específica para ello (Jauset, 2008). Van der Zwaag, Westerink, y Van den Broek (2011) llegan a la conclusión de que las características musicales de tempo y modo interactúan con las emociones.

Para percibir emociones a través de la música, Baumgartner, Lutz, Schmidt, y Jäncke (2005), comprobaron que imágenes acompañadas de música podían provocar respuestas cognitivas de la percepción de la emoción. Los individuos que se sometieron a las indagaciones de estos investigadores experimentaron sensaciones fuertes, captando la intención de las imágenes casi en su totalidad. 
Panksepp y Bernatzky (2002) revisaron las formas en las que la música puede promover cambios emocionales y comportamentales, incluyendo sus efectos sobre la memoria, el estado de ánimo, la actividad cerebral y las respuestas autonómicas como los escalofríos (ante una audición musical). Estos investigadores dicen que la música es el lenguaje de las emociones.

En relación con la aparición en el mercado de instrumentos válidos que evalúen música y emoción, Juslin y Sloboda (2010) hablan de las dificultades que se presentan para poder investigar rigurosamente sobre emoción musical: no hay procedimiento científico estandarizado, la dificultad de selección adecuada de la música que genere emociones particulares, o el uso de música real como estímulo experimental, son algunas de las barreras que se presentan. Sin embargo, gracias a las técnicas de imágenes cerebrales no invasivas de las que se dispone actualmente, se han podido analizar estados cognitivos evocados por músicas diferentes.

No se conocen estudios donde se presenten instrumentos de medición de identificación emocional a través de la música. Sí existe alguno donde se aportan evidencias para la validación de la conexión entre música y emociones (AlaminosFernández, 2014). Por otro lado, también se ha demostrado el poder predictor que tiene la Inteligencia Emocional en el rendimiento académico y más concretamente en el rendimiento musical (Martín-López y León, 2009) y que los estímulos musicales pueden modificar las percepciones de un determinado resultado académico (Pérez y Nicolau, 2011); pero, actualmente, las autoras de esta investigación no conocen ningún instrumento válido y fiable que mida la identificación emocional a través de la música.

\section{MÉTODO}

\section{Participantes}

La muestra estuvo compuesta por alumnos y alumnas de dos facultades de la Universidad Complutense de Madrid: Educación y Trabajo Social $(N=430)$. También se recogieron datos de alumnado de la Universidad de Sofía (Bulgaria) $(N=84)$. La prueba, para el alumnado de la universidad de Sofía, fue traducida al búlgaro.

Los estudiantes de la facultad de Educación eran mayoritariamente de $3^{\circ}$ y $4^{\circ}$ de Grado de Magisterio de las especialidades de Infantil y de Primaria, y una muestra minoritaria de Máster en Educación Musical. Los estudiantes de la facultad de Trabajo Social cursaban $1^{\circ}$ Grado. El alumnado búlgaro de la universidad de Sofía cursaba estudios de logopedia (ver Tabla 1). Toda la recogida de datos se realizó durante el año académico 2016-2017. 
Tabla 1. Distribución de la muestra por especialidades

\begin{tabular}{llcccc}
\hline & & Frecuencia & Porcentaje & $\begin{array}{c}\text { Porcentaje } \\
\text { válido }\end{array}$ & $\begin{array}{c}\text { Porcentaje } \\
\text { acumulado }\end{array}$ \\
\hline \multirow{5}{*}{ Especialidades } & Educación Infantil & 123 & 23.9 & 23.9 & 23.9 \\
\cline { 2 - 6 } & Educación Primaria & 74 & 14.4 & 14.4 & 38.3 \\
\cline { 2 - 6 } & Educación Musical & 33 & 6.4 & 6.4 & 44.7 \\
\cline { 2 - 6 } & Trabajo Social & 200 & 38.9 & 38.9 & 83.7 \\
\cline { 2 - 6 } & Logopedia & 84 & 16.3 & 16.3 & 100 \\
\cline { 2 - 6 } & Total & 514 & 100 & 100 & \\
\hline
\end{tabular}

Todos ellos conformaron una población comparable de sujetos con edades comprendidas entre los 18 y 40 años; siendo la media de edad de 22.5 años, con un porcentaje del $81 \%$ de muestra femenina (ver Tabla 2).

Tabla 2. Distribución de la muestra por género y edades

\begin{tabular}{lcccccc}
\hline \multicolumn{1}{c}{ Sexo } & Media edad & $N$ & Porcentaje & $\begin{array}{c}\text { Desviación } \\
\text { estándar }\end{array}$ & Mínimo Máximo \\
\hline Masculino & 21.74 & 97 & 18.9 & 2.38 & 18 & 30 \\
\hline Femenino & 22.73 & 417 & 81.1 & 4.9 & 18 & 40 \\
\hline Total & 22.54 & 514 & 100 & 4.55 & 18 & 40 \\
\hline
\end{tabular}

En la recogida de datos se registró también si tenían estudios musicales adicionales al currículum educativo oficial (ver Tabla 3).

Tabla 3. Distribución de la muestra por estudios musicales

\begin{tabular}{clcccc}
\hline & Frecuencia & Porcentaje & $\begin{array}{c}\text { Porcentaje } \\
\text { válido }\end{array}$ & $\begin{array}{c}\text { Porcentaje } \\
\text { acumulado }\end{array}$ \\
\hline \multirow{2}{*}{ Válido } & Sin estudios musicales & 426 & 82.9 & 82.9 & 82.9 \\
\cline { 2 - 6 } & Con estudios musicales & 88 & 17.1 & 17.1 & 100 \\
\cline { 2 - 6 } & Total & 514 & 100 & 100 & \\
\hline
\end{tabular}

\section{Instrumento}

EMÚ, en esta primera versión, consta de dos partes bien diferenciadas:

En la parte 1 se presentan ocho parejas de imágenes y ocho fragmentos musicales del repertorio clásico escrupulosamente seleccionados. Los fragmentos musicales (ver Tabla 4) se van presentando de uno en uno y el sujeto debe seleccionar uno de los dos componentes de la pareja de imágenes presentadas. Las instrucciones indican lo siguiente: "Vas a escuchar ocho fragmentos de música. Marca la imagen que consideres más adecuada según el fragmento escuchado". Las cuatro primeras parejas de imágenes se identifican con una de las características fundamentales de la música: "rápido-lento". Respecto a las cuatro segundas parejas de imágenes, la característica que les identifica es "fuerte-suave". 
Tabla 4. Estructura Parte 1

\begin{tabular}{cccc}
\hline $\begin{array}{c}\text { Rápido (R)/ } \\
\text { Lento (L) }\end{array}$ & Fragmento musical & $\begin{array}{c}\text { Fuerte (F)/ } \\
\text { Suave (S) }\end{array}$ & Fragmento musical \\
\hline 1 R & Paganini_Caprice N ${ }^{\circ}$.24 in A-min & $1 \mathrm{~F}$ & Wagner_La cabalgata de las Valkirias \\
\hline 2 L & Bach_Concerto 5 in F minor & $2 \mathrm{~F}$ & Beethoven_Symphony n 5 \\
\hline $3 \mathrm{R}$ & $\begin{array}{c}\text { Rimsky Korsakov_El vuelo del } \\
\text { moscardón }\end{array}$ & $3 \mathrm{~S}$ & Vivaldi_Concerto 2 Mandolins in G \\
\hline 4 L & Beethoven_Claro de luna & 4 S & Mozart_Flute and Harp Concerto in C \\
\hline
\end{tabular}

La parte 2 se subdivide, a su vez, en dos (2A y 2B). La primera de ellas (2A) pretende medir la identificación emocional a través de la música. La instrucción dada es: "Vas a escuchar seis fragmentos de música. Relaciona la música escuchada con una de las siguientes imágenes. Marca la imagen elegida según el orden de la música escuchada". En esta ocasión, se presentan seis imágenes (caras anónimas) que reflejan emociones primarias y secundarias distintas: miedo, alegría, ira, tristeza, paz o serenidad y amor. Estas imágenes deben ser asociadas con seis fragmentos de música clásica distintos a los de la primera parte de la prueba, pero también seleccionadas con rigor (ver Tabla 5). Las audiciones se reprodujeron una por una y el sujeto debía elegir una de las seis imágenes presentadas. Existía la posibilidad de cambiar la elección según se iba avanzando en las distintas audiciones, pero no se repetía la audición de ninguno de los fragmentos musicales. La segunda parte (2B) consiste en dibujar cuatro elementos básicos de un rostro que representan una emoción concreta (expresión emocional). Las instrucciones indican: "Vas a escuchar cuatro fragmentos de diferentes piezas musicales. Una vez escuchada cada una de ellas, dibuja en cada cara: ojos, nariz, boca y cejas". En esta ocasión, se presentan cuatro perfiles de rostros vacíos que se tienen que completar con los elementos antes mencionados. Se presentan cuatro fragmentos musicales, casi todos distintos de los anteriores, de uno en uno, y el sujeto debe completar cada uno de los cuatro rostros asociando lo dibujado con una emoción. Las músicas seleccionadas transmiten: alegría, miedo, ira y tristeza (ver Tabla 5).

Tabla 5. Estructura Parte 2

\begin{tabular}{|c|c|c|c|}
\hline & Identificación emocional (2A) & & Expresión emocional (2B) \\
\hline Emoción & Fragmento musical & Emoción & Fragmento musical \\
\hline Miedo & $\begin{array}{c}\text { Carl_Orff_O_Fortuna-Carmina } \\
\text { Burana }\end{array}$ & Alegría & Mozart_Turkish March \\
\hline Alegría & Vivaldi - Spring & Miedo & Beethoven $-5^{\text {a }}$ sinfonía \\
\hline Ira & Prokofiev_Toccata_D & Ira & $\begin{array}{c}\text { Shostakovich } 7^{\text {a }} \text { sinfonía en Do Mayor } \\
\text { (Leningrado) }\end{array}$ \\
\hline Tristeza & Pau Casals_El_cant dels ocells & Tristeza & Pau Casals_El_cant_dells_ocells \\
\hline $\mathrm{Paz}$ & E_Grieg_Amanecer & & \\
\hline Amor & Chopin - Nocturne Op. $9, \mathrm{~N}^{\circ} 2$ & & \\
\hline
\end{tabular}


Las obras seleccionadas para evocar la emoción de alegría tienen características musicales que les relacionan con una emoción positiva. Una de ellas es el tono mayor. Otras son el tempo rápido sin disonancias y el desarrollo de la melodía de forma ascendente.

El miedo como emoción se ha tratado de identificar a través de la parte " $O$ Fortuna" de la cantata "Carmina Burana" de Carl Orff porque tiene rasgos que la distinguen de la música de ira, como la ausencia de disonancias irritantes. La otra obra que se ha considerado para representación del miedo es el comienzo de la "Quinta sinfonía" de Beethoven. Aquí el comienzo expresa una llamada con malas intenciones (es tono menor, intervalo descendente en forte).

Las obras elegidas para inducir la emoción de ira son la "Séptima Sinfonía en Do mayor" de Shostakovich, primera parte y la "Toccata en Re menor" de Prokofiev. Los instrumentos dominantes de la primera obra son de viento y abundan las disonancias. La obra de Prokofiev no suscita dudas: la repetición muy rápida de una nota con las interrupciones disonantes se convierte en ira por la insistencia prolongada de molestas irritaciones.

La obra considerada más significativa para la tristeza ha sido "El cant dells ocells" del catalán Pau Casals. El desarrollo de la melodía lenta, con notas prolongadas y en tono menor representa una tristeza y un llanto contenido. Únicamente se repite este fragmento de música en EMÚ por ser considerado popularmente como uno de los fragmentos musicales más tristes del mundo.

La obra elegida para evocar paz o serenidad fue "Amanecer" de Edvard Grieg. $\mathrm{Su}$ tono mayor, la orquesta y los instrumentos solistas de viento y de cuerdas incitan a sentir movimientos suaves y alegres que provocan serenidad.

Por último, el amor se ha querido incitar desde la ternura y la amistad, más que desde la pasión. La razón es porque se pretende que el instrumento sea válido también desde la etapa de Educación Infantil. La obra elegida ha sido el "Nocturno Opus 9, N. ${ }^{\circ}$ " de Chopin, donde se percibe un deseo de ternura y amor.

En ambas partes de EMÚ la presentación de los fragmentos musicales tiene una duración de 20 segundos cada uno.

\section{Procedimiento}

La administración de la prueba duró veinte minutos y se realizó en el aula donde se imparten las clases de las investigadoras del presente estudio en grupos entre 25 y 30 sujetos. Se les entregó a los participantes una copia de EMÚ en papel, se leyeron las instrucciones en voz alta y se atendieron las dudas que pudieran surgir. Se les aseguró la protección de datos y se les dio garantías de confidencialidad. A continuación, se expusieron de uno en uno los fragmentos de música seleccionados. Los sujetos iban marcando la imagen que pensaban que mejor encajaba con la música escuchada. En la 
última parte de la prueba (2B) se les indicó que no se les evaluaba la calidad del dibujo sino la capacidad que tenían para expresar emociones básicas con rasgos sencillos

\section{Análisis de datos}

Como primer paso se operativizaron las respuestas de los participantes en aciertos y errores. A continuación, se pasó a tratar los datos mediante la herramienta SPSS (v22). En un principio se obtuvieron datos estadísticos de tipo descriptivo para analizar las puntuaciones medias y desviaciones típicas de la muestra. Posteriormente, los análisis se centraron en la búsqueda de la significatividad de las diferencias entre distintos aspectos (especialidades, sexo, estudios musicales,...) utilizando para ello un ANOVA, así como la prueba de Kruskal Vallis para muestras no paramétricas. Además, se aplicó la prueba de Turkey con el fin de profundizar en los resultados. Para analizar la fiabilidad de la prueba se utilizó el alfa de Cronbach. El resultado del análisis de la fiabilidad como consistencia interna muestra que la parte de identificación emocional a través de la música clásica (2A) es la que puede darse como aceptable con un alfa de Cronbach de .71

\section{RESULTADOS}

En un primer momento se realizó un análisis de la fiabilidad total de la prueba (parte 1 y parte 2) obteniendo un alfa de Cronbach poco consistente (ver Tabla 6) por lo que se pasó a analizar la prueba por partes. Después de realizar diversos análisis estadísticos, se observó que la parte más consistente de EMÚ es la parte $2 \mathrm{~A}$ (identificación de la emoción a través de la música) obteniéndose un alfa bastante más aceptable (ver Tabla 6).

Tabla 6. Estadísticas de fiabilidad

\begin{tabular}{lcc}
\hline & Alfa de Cronbach & N de elementos \\
\hline Test completo & .60 & 18 \\
\hline Parte 2A & .71 & 6 \\
\hline
\end{tabular}

$\mathrm{Al}$ analizar la consistencia de esta parte ítem por ítem se puede considerar que los ítems miden la misma variable latente (ver Tabla 7).

Tabla 7. Estadísticas de total elemento de parte 2

\begin{tabular}{lcccc}
\hline & $\begin{array}{c}\text { Media de escala si el } \\
\text { elemento se ha suprimido elemento se ha suprimido }\end{array}$ & $\begin{array}{c}\text { Varianza de escala si el } \\
\text { elementos corregida }\end{array}$ & $\begin{array}{c}\text { Correlación total de } \\
\text { elemento se ha suprimido }\end{array}$ \\
\hline $2 \mathrm{~A} 1$ & 3.78 & 2.02 & .39 & .68 \\
\hline $2 \mathrm{~A} 2$ & 3.8 & 2 & .39 & .68 \\
\hline $2 \mathrm{~A} 3$ & 3.8 & 1.98 & .41 & .68 \\
\hline $2 \mathrm{~A} 4$ & 3.7 & 2.07 & .45 & .67 \\
\hline $2 \mathrm{~A} 5$ & 3.86 & 1.80 & .53 & .64 \\
\hline $2 \mathrm{~A} 6$ & 3.75 & 1.96 & .48 & .66 \\
\hline
\end{tabular}


Para realizar un análisis correlacional entre las distintas partes de EMÚ, en primer lugar, se sumaron las puntuaciones de los diferentes ítems que conformaban cada parte; es decir, cuatro ítems de $1 \mathrm{~A}$, cuatro ítems de $1 \mathrm{~B}$, seis ítems de $2 \mathrm{~A}$ y cuatro ítems de $2 \mathrm{~B}$. Al realizar el análisis se observan diferencias significativas entre todas las partes del test (ver Tabla 8).

Tabla 8. Correlaciones entre las distintas partes de EMÚ

\begin{tabular}{|c|c|c|c|c|c|}
\hline & & 1A SUMA & 1B SUMA & 2A SUMA & 2B SUMA \\
\hline \multirow{3}{*}{ 1A SUMA } & $\begin{array}{c}\text { Correlación de } \\
\text { Pearson }\end{array}$ & 1 & $.28^{* *}$ & $.17^{* *}$ & $.11^{*}$ \\
\hline & Sig. (bilateral) & & .00 & .00 & .01 \\
\hline & $\mathrm{N}$ & & 514 & 514 & 514 \\
\hline \multirow{3}{*}{ 1B SUMA } & $\begin{array}{c}\text { Correlación de } \\
\text { Pearson }\end{array}$ & & 1 & $.14^{* *}$ & $.10^{*}$ \\
\hline & Sig. (bilateral) & & & .00 & .02 \\
\hline & $\mathrm{N}$ & & & 514 & 514 \\
\hline \multirow{3}{*}{ 2A SUMA } & $\begin{array}{c}\text { Correlación de } \\
\text { Pearson } \\
\end{array}$ & & & 1 & $.09^{*}$ \\
\hline & Sig. (bilateral) & & & & .02 \\
\hline & $\mathrm{N}$ & & & & 514 \\
\hline \multirow{3}{*}{ 2B SUMA } & $\begin{array}{c}\text { Correlación de } \\
\text { Pearson } \\
\end{array}$ & & & & 1 \\
\hline & Sig. (bilateral) & & & & \\
\hline & $\mathrm{N}$ & & & & \\
\hline
\end{tabular}

En relación con el sexo, los datos muestran que hay diferencias entre las medias de los chicos y chicas, a favor de estas últimas. Sin embargo, estas diferencias no son significativas excepto en la parte $1 \mathrm{~B}$ donde el nivel de significatividad del test Anova F es =.003 (ver Tabla 9).

Tabla 9. Diferencias por sexo

\begin{tabular}{lccccc}
\hline & Sexo & $\mathrm{N}$ & Media & $\begin{array}{c}\text { Desviación } \\
\text { estándar }\end{array}$ & $\begin{array}{c}\text { Media de error } \\
\text { estándar }\end{array}$ \\
\hline \multirow{2}{*}{ 1A SUMA $p=.481$} & Femenino & 417 & 3.34 & .68 & .03 \\
\hline & Masculino & 97 & 3.28 & .8 & .08 \\
\hline \multirow{2}{*}{ B SUMA $p=.003$} & Femenino & 417 & 3.25 & .78 & .03 \\
\cline { 2 - 6 } 2A SUMA $p=.115$ & Masculino & 97 & 2.98 & .81 & .08 \\
\hline \multirow{2}{*}{ 2B SUMA $p=.617$} & Femenino & 417 & 4.6 & 1.58 & .07 \\
\cline { 2 - 6 } & Masculino & 97 & 4.29 & 1.78 & .18 \\
\hline & Femenino & 417 & 4.25 & 1.88 & .09 \\
\hline
\end{tabular}

Comparando las medias según si los sujetos tienen o no estudios musicales, los datos muestran que las diferencias entre ambos grupos no son significativas, excepto en la parte 1B, donde el nivel de significatividad es <.05 (ver Tabla 10). 
Tabla 10. Diferencias por conocimientos musicales

\begin{tabular}{llcccc}
\hline & Estudios Musicales & $\mathrm{N}$ & Media & $\begin{array}{c}\text { Desviación } \\
\text { estándar }\end{array}$ & $\begin{array}{c}\text { Media de } \\
\text { error estándar }\end{array}$ \\
\hline \multirow{2}{*}{ 1A SUMA $p=.124$} & Con estudios musicales & 88 & 3.43 & .65 & .07 \\
\cline { 2 - 6 } & Sin estudios musicales & 426 & 3.31 & .72 & .03 \\
\hline \multirow{2}{*}{ 1B SUMA $p=.032$} & Con estudios musicales & 88 & 3.23 & .77 & .08 \\
\cline { 2 - 6 } & Sin estudios musicales & 426 & 3.19 & .8 & .04 \\
\hline \multirow{2}{*}{ 2A SUMA $p=.093$} & Con estudios musicales & 88 & 4.47 & 1.6 & .16 \\
\cline { 2 - 6 } & Sin estudios musicales & 426 & 4.56 & 1.64 & .08 \\
\hline \multirow{2}{*}{ 2B SUMA $p=.230$} & Con estudios musicales & 88 & 4.51 & 1.94 & .2 \\
\cline { 2 - 6 } & Sin estudios musicales & 426 & 4.17 & 2.03 & .01 \\
\hline
\end{tabular}

Si nos fijamos en las medias obtenidas por especialidades, se han registrado diferencias significativas. Se ha aplicado la prueba de Kruskal Vallis para muestras no paramétricas y la significatividad es de .000 (ver Tabla 11).

Tabla 11. Significatividad para muestras no paramétricas

\begin{tabular}{lcccc}
\hline \multicolumn{5}{c}{ Estadísticos de prueba ${ }^{\mathrm{a}, \mathrm{b}}$} \\
\hline & $1 \mathrm{~A}$ & $1 \mathrm{~B}$ & $2 \mathrm{~A}$ & $2 \mathrm{~B}$ \\
\hline Chi-cuadrado & 45.25 & 42.46 & 37.6 & 85.56 \\
\hline gl & 4 & 4 & 4 & 4 \\
\hline Sig. asintótica & .00 & .00 & .00 & .00 \\
\hline
\end{tabular}

a. Prueba de Kruskal Wallis

b. Variable de agrupación: Especialidades

A continuación, y para entrar en detalles, se ha aplicado la prueba de Tukey que demuestra que las variables con letra A son significativamente diferentes de las variables con la letra $B$. No tienen letra aquellas, que no son significativamente diferentes ni del A ni del B (ver Tabla 12).

Tabla 12. Diferencias por especialidades

\begin{tabular}{|c|c|c|c|c|}
\hline & Especialidades & $\mathrm{N}$ & Media & Desviación estándar \\
\hline \multirow{5}{*}{ 1A SUMA $p<.0001$} & Educación Infantil B & 123 & 3.6 & .6 \\
\hline & Educación Primaria & 74 & 3.4 & .64 \\
\hline & Educación Musical B & 33 & 3.5 & .67 \\
\hline & Trabajo Social A & 200 & 3.2 & .7 \\
\hline & Logopedia A & 84 & 3.1 & .79 \\
\hline \multirow{5}{*}{ 1B SUMA $p<.0001$} & Educación Infantil B & 123 & 3.5 & .6 \\
\hline & Educación Primaria & 74 & 3.2 & .75 \\
\hline & Educación Musical B & 33 & 3.5 & .66 \\
\hline & Trabajo Social A & 200 & 3 & .81 \\
\hline & Logopedia A & 84 & 3 & .89 \\
\hline \multirow{5}{*}{ 2A SUMA $p<.0001$} & Educación Infantil B & 123 & 5.1 & 1.3 \\
\hline & Educación Primaria B & 74 & 4.9 & 1.5 \\
\hline & Educación Musical & 33 & 4 & 1.9 \\
\hline & Trabajo Social A & 200 & 4.4 & 1.5 \\
\hline & Logopedia A & 84 & 3.9 & 1.8 \\
\hline \multirow{5}{*}{ 2B SUMA $p<.0001$} & Educación Infantil B & 123 & 4.7 & 1.6 \\
\hline & Educación Primaria B & 74 & 3.8 & 1.7 \\
\hline & Educación Musical A & 33 & 4.8 & 1.7 \\
\hline & Trabajo Social A & 200 & 3.4 & 2.2 \\
\hline & Logopedia A & 84 & 5.3 & 1.7 \\
\hline
\end{tabular}


Los resultados referidos a la identificación y expresión de las emociones muestran diferencias apreciables entre ellas (ver Tabla 13).

Tabla 13. Resultados obtenidos en Parte 2

\begin{tabular}{lccc}
\hline Parte 2A & $\begin{array}{c}\text { Porcentaje } \\
\text { aciertos 2A }\end{array}$ & Parte 2B & $\begin{array}{c}\text { Porcentaje } \\
\text { aciertos 2B }\end{array}$ \\
\hline Tristeza & $84.2 \%$ & Tristeza & $80.4 \%$ \\
\hline Amor & $78.4 \%$ & Alegría & $79 \%$ \\
\hline Miedo & $76 \%$ & Ira & $52.5 \%$ \\
\hline Alegría & $73.5 \%$ & Miedo & $47.5 \%$ \\
\hline Ira & $73.5 \%$ & & \\
\hline Paz & $67.5 \%$ & & \\
\hline
\end{tabular}

\section{DISCUSIÓN Y CONCLUSIONES}

La parte 2A de EMÚ tiene una buena consistencia interna presentando un alfa de .71. Con alta probabilidad se puede afirmar que mide el rasgo de identificación emocional a través de la música clásica, partiendo de imágenes mostradas. El apoyo visual ayuda a la percepción e identificación de la emoción (Baumgartner, Lutz, Schmidt, y Jäncke, 2005). Emociones básicas como son la alegría y la tristeza son identificadas claramente por los participantes del estudio. Llama la atención cómo la tristeza es la emoción más identificada y expresada. Esto puede ser debido a que el ejemplo musical que evocaba tristeza ha conectado mejor y/o que a los jóvenes objeto de la muestra les resulta más fácil identificar y expresar la tristeza a través de la música clásica, como analizan Vallés y Vallés (2000).

Por otro lado, las pruebas de diferencias de medias han evidenciado que no existe una diferencia significativa en las puntuaciones de la prueba en función de los conocimientos musicales previos que tienen los sujetos. Probablemente puede ser por la diferencia que existe en el número de la muestra entre los que no tienen conocimientos musicales $(N=426)$ y los que sí tienen ese tipo de conocimiento $(N=88)$. Sin embargo, hay que considerar que, aunque sean menos sujetos, puntúan más en la parte 1 y en la 2B, es decir, obtienen mejores resultados en identificar cualidades de la música como fuerte/suave y rápido/lento con imágenes dadas, así como son más capaces de plasmar rasgos básicos de las emociones ante una música dada. Es lógico pensar que los conocimientos musicales van a ayudar a identificar cualidades de la música como son la intensidad y la velocidad (partes 1A y 1B). Saben, por ejemplo, que la mayor velocidad (tempo) se asocia con excitación y menor velocidad con relajación (Caballero-Meneses y Menez, 2010), aspectos ambos muy relacionados con las emociones (Van der Zwaag, Westerink, y Van den Broek, 2011).

Por otro lado, el que hayan puntuado ligeramente por debajo que los sujetos sin conocimientos musicales en la parte $2 \mathrm{~A}$ puede ser debido a que analizan las 
características de la música escuchada utilizando sus conocimientos para un análisis más cognitivo que emocional; sin embargo, esto no sucede cuando la tarea es dibujar los rasgos básicos de las cuatro emociones primarias ya comentadas. En este caso, puede que se dejen llevar más por lo emotivo y dibujen los rasgos según lo que les transmite el fragmento musical desde el punto de vista emocional. Esta parte de la prueba no muestra estímulos visuales sobre los que fijarse para elegir uno (como sucede en la parte $2 \mathrm{~A}$ de identificación emocional, donde la atención debe estar focalizada en las seis imágenes, además de en la música) sino que lo que se presenta es la silueta de un rostro en blanco. En este caso, la atención solo debe concentrarse en la música escuchada para realizar la tarea de expresión emocional.

Respecto al sexo, se ha comprobado que, aunque no haya significatividad en los resultados, las chicas han obtenido mejores puntuaciones. Estos resultados coinciden con lo ya argumentado por Salovey y Mayer (1990) en relación con la inteligencia emocional y más concretamente a la percepción de la emoción entendida como la habilidad para identificar las propias emociones y las de los demás teniendo la destreza de fijar la atención en expresiones faciales (en la prueba EMU, las imágenes que se presentan son expresiones faciales) (Fernández-Berrocal y Extremera, 2005).

En cuanto a los análisis realizados por especialidades los estudiantes de Educación Infantil han obtenido los mejores resultados en las partes 1A, 1B y $2 \mathrm{~A}$, seguidos por los de Educación Musical que han obtenido sus mejores resultados en las partes 1A y 1B y los de Educación Primaria que han destacado en la parte 2A. Un aspecto interesante es el observar que los estudiantes de Logopedia, aun siendo los que peores resultados han obtenido en la identificación de las características musicales y de las emociones, han sido los mejores en la expresión de las emociones a través del dibujo. Puede que estén más familiarizados con el uso de pictogramas (que es lo que se ha utilizado para responder a esta parte de la prueba EMU) como sistemas aumentativos y/o alternativos de comunicación en población con trastorno de espectro autista.

En relación con las limitaciones, una de ellas ha sido el escaso número de chicos que han conformado la muestra. Las carreras universitarias en las que se ha realizado la investigación son mayoritariamente femeninas. También habría que señalar como limitación el corto número de ítems que forman cada parte de EMU. Puede ser una de las causas por las que varias de sus partes no hayan obtenido una varianza más amplia y una consistencia interna más fuerte. También ha existido la dificultad de encontrar muestra que tuviera estudios musicales.

Ante las limitaciones admitidas, las futuras líneas de investigación comprometen a los siguientes aspectos: ampliar el número de ítems en cada parte de EMÚ con el objetivo de poder obtener una mayor validez, administrar la prueba a sujetos con mayor variabilidad de edad (incluyendo alumnado desde los 3 años), también administrarlo a mayor cantidad de músicos, así como a mayor número de chicos. Otras 
sugerencias que aportamos tienen que ver con registrar la lateralidad de los participantes con el objetivo de averiguar si las personas zurdas tienen mayor facilidad para reconocer las emociones a través de la música, al tener dominante el hemisferio cerebral derecho que es donde se localiza la mayor parte de la creatividad de los individuos y la música implica procesos creativos. Por último, nos gustaría añadir también a EMU algún ítem donde se pueda extraer información sobre la percepción de la dificultad de la tarea que tienen los sujetos antes y después de realizarla (aplicación de estrategias metacognitivas teniendo en cuenta la variable tarea).

\section{REFERENCIAS}

Alaminos-Fernández, A.F. (2014). La música como lenguaje de las emociones. Un análisis empírico de su capacidad performativa. [Music as a language of emotions. An empirical Analysis of its performative capacity]. OBETS. Revista de Ciencias Sociales, 9(1), 1542. doi:10.14198/OBETS2014.9.1.01

Baumgartner, T., Lutz, K., Schmidt, C., y Jäncke, L. (2005). The emotional power of music: How music enhances the feeling of affective pictures. Brain Research, 1075, 151-164. doi:10.1016/j.brainres.2005.12.065

Caballero-Meneses, J., y Menez, M. (2010). Influencia del tempo de la música en las emociones. Revista Colombiana de Psicología, 19(1), 37-44. doi:10.15446/rcp

Ekman, P. (1992). An Argument for Basic Emotions. Cognition and Emotion, 6(3), 169-200. doi:10.1080/02699939208411068

Fernández-Abascal, E.G. (2011). Emociones positivas. Madrid: Pirámide.

Fernández-Berrocal, P., y Extremera, N. (2005). La Inteligencia Emocional y la educación de las emociones desde el modelo de Mayer y Salovey. Revista Interuniversitaria de Formación del Profesorado, 19(3), 63-93.

Fritz, T., Jentschke, S., Gosselin, N., Sammier, D., Peretz, I., Turner, R., Friederici, A., y Koelsch, S. (2009). Universal Recognition of Three Basic Emotions in Music. Current Biology, 19(7), 573-576. doi:10.1016/j.cub.2009.02.058

Jauset, J. (2008). Música y Neurociencia: la musicoterapia sus fundamentos, efectos y aplicaciones terapéuticas. Barcelona: Universitat Oberta de Catalunya.

Jiménez, V. (2011). Psicología Positiva. En A. Puente (Eds.). Psicología Contemporánea Básica y Aplicada. Madrid: Pirámide.

Juslin, P., y Sloboda, J. (2010). Handbook of Music and Emotion. Theory, Research, Applications. NY: Oxford University Press.

Lacárcel, J. (2003). Psicología de la música y emoción musical. Educatio, 20-21, 213-226.

Levitin, D.J. (2015). Tu cerebro y la música. El estudio científico de una obsesión humana. Barcelona: Grupo RBA.

Martín-López, E.M., y León, B. (2009). Inteligencia emocional y rendimiento musical. Campo Abierto. Revista de Educación, 28(1), 119-127.

Mohn, C., Argstatter, H., y Wilker, F.W. (2011) Perception of six basic emotions in music. Psychology of Music, 39(4), 503-517. doi:10.1177/0305735610378183

Mosquera, I. (2013). Influencia de la música en las emociones: una breve revisión. Realitas, Revista de Ciencias Sociales, Humanas y Artes, 1(2), 34-38. 
Panksepp, J., y Bernatzky, G. (2002). Emotional sounds and the brain: the neuro-affective foundations of musical appreciation. Behavioural Processes, 60, 130-155 doi:10.1016/S0376-6357(02)00080-3

Pérez, P., y Nicolau, J.L. (2013). Testing prospect theory in student's performance. Revista de Educación, 360, 645-665. doi: 10.4438/1988-592X-RE-2013-360-216

Salovey, P., y Mayer, J. (1990). Emotional Intelligence. Imagination, Cognition and Personality, 9, 185-211.

Vallés, A., y Vallés, C. (2000). Inteligencia Emocional. Aplicaciones educativas. Madrid: Editorial EOS.

Van der Zwaag, M., Westerink, J.H.D.M., y Van den Broek, E. (2011). Emotional and psychophysiological responses to tempo, mode and percussiveness. Musicae Scientiae, 15(2), 250-269. doi:10.1177/102986491101500207

Recibido: 12 de julio de 2019 Recepción Modificaciones: 28 de julio de 2019

Aceptado: 17 de septiembre de 2019 